\title{
Effects of varicocele on testosterone, apoptosis and expression of StAR mRNA in rat Leydig cells
}

\author{
De-Yi Luo ${ }^{1}$, Gang Yang ${ }^{2}$, Jian-Jun Liu ${ }^{3}$, Yu-Ru Yang ${ }^{1}$ and Qiang Dong ${ }^{1}$
}

The aim of this study was to explore the effects of varicocele on the morphology and function of Leydig cells in the rat testis. Forty male Sprague-Dawley rats were divided into two groups: the experimental group underwent surgery to create a left varicocele (VC), and the control group underwent a sham operation. Serum testosterone and intratesticular testosterone levels were measured using a radioimmunoassay after 4 and 8 weeks of operation. Leydig cells were studied for apoptosis and expression of steroidogenetic acute regulatory (StAR) protein mRNA levels. Serum testosterone levels declined after 4 and 8 weeks of operation but were not significant $(P>0.05)$. However, the intratesticular testosterone levels after 8 weeks were significantly decreased compared with the control group $(P<0.01)$. The mean apoptosis index of Leydig cells in the experimental group was significantly higher than that in the control group after 4 or 8 weeks $(P<0.01)$. StAR mRNA levels in the Leydig cells of the experimental group were significantly lower compared to those of the control group $(P<0.01)$. Our data show that varicocele did impair Leydig cell function by increasing apoptosis and suppressing the expression of the StAR protein. Asian Journal of Andrology (2011) 13, 287-291; doi:10.1038/aja.2010.111; published online 15 November 2010

Keywords: apoptosis; Leydig cell; steroidogenic acute regulatory protein; testosterone; varicocele

\section{INTRODUCTION}

Varicocele (VC) is a common disorder in men. Although it is considered as one of the leading causes of male infertility, ${ }^{1}$ the mechanism is still unclear. The incidence of $\mathrm{VC}$ in the general population is approximately $15 \%$, but $19-41 \%$ of men with infertility have VC. ${ }^{2}$ Numerous studies have shown that VC could lead to dysfunction of spermatogenesis including decreases in sperm count and motility. ${ }^{3-5}$ It is known that VC is associated with male infertility. ${ }^{6}$ Various hypotheses have been proposed to explain the underlying mechanism, including increase in temperature, backflow of metabolites from the adrenal gland, accumulation of $\mathrm{CO}_{2}$ and nitric oxide, and autoimmunity. ${ }^{7-9}$ Because the basic function of the Leydig cells is testosterone biosynthesis and secretion as well as spermatogenesis, studies on Leydig cell dysfunction have become an important area of research in male infertility. However, the effects of VC on Leydig cells are poorly understood. Testosterone levels depend on the number of Leydig cells and on the capacity of a single cell to produce testosterone. Additionally, several studies have reported decreases in testosterone levels in serum from VC patients. ${ }^{10,11}$ Ghosh and York ${ }^{12}$ and Zheng et al. ${ }^{13}$ found that intratesticular testosterone levels decrease in $\mathrm{VC}$, which directly affects spermatogenesis. The current study aimed to evaluate the effects of VC on testosterone production, apoptosis and expression of steroidogenetic acute regulatory (StAR) mRNA in rat Leydig cells.

\section{MATERIALS AND METHODS}

\section{Animals}

Forty male Sprague-Dawley rats aged 6-7 weeks and weighing 220-300 g were randomly divided into two groups. Animals were kept in individual cages at a constant temperature $\left(22 \pm 2{ }^{\circ} \mathrm{C}\right)$ under a $12 \mathrm{~h}$ light $/ 12 \mathrm{~h}$ dark cycle and were fed standard rat chow with free access to tap water. Before surgery, animals were fasted for $12 \mathrm{~h}$ with free access to water. Animals in the experimental group underwent surgery to produce a left $\mathrm{VC}$, whereas the control group underwent a sham operation. All rats were obtained from the Laboratory Animal Center of West China School of Preclinical and Forensic Medicine (Chengdu, China) and were treated in accordance with the Guide for the Care and Use of Laboratory Animals. ${ }^{14}$ The study was approved by the ethical committee of West China School of Medicine, Sichuan University (Chengdu, China).

\section{Surgical procedure}

Animals were anesthetized by an intraperitoneal injection of $5 \%$ chloral hydrate $\left(6 \mathrm{ml} \mathrm{kg}^{-1}\right)$. The left renal vein located between the inferior vena cava and the left spermatic vein was isolated. In the experimental group, the renal vein was ligated by a 3-0 silk suture using a needle $(0.55 \mathrm{~mm}$ in diameter). Then the needle was removed to induce a partial stenosis of the left renal vein (Figure 1). The VC was observed when the pressure was transmitted to the left spermatic vein (Figure 2). The wound was closed with a 3-0 silk suture. In the control group, rats underwent a similar procedure but without ligation of the renal vein.

\section{Radioimmunoassay}

Blood samples from the inferior vena cava were collected between 9:00 and 11:00 a.m. at 4 and 8 weeks post-operation. Serum was prepared by centrifugation $(3000 \mathrm{~g})$ and stored frozen at $-30{ }^{\circ} \mathrm{C}$. Serum testosterone levels were measured by radioimmunoassay. Testes (100 $\mathrm{mg})$ were homogenized in $70 \%$ methanol $(300 \mathrm{ml}$ of methanol). The

${ }^{1}$ Department of Urology, West China Hospital, Sichuan University, Chengdu 610041, China; ${ }^{2}$ Department of Pediatric Surgery, West China Hospital, Sichuan University, Chengdu 610041, China and ${ }^{3}$ Department of Urology, People's Hospital, Henan 450003, China Correspondence: Professor Q Dong (dqiang@gmail.com)

Received: 23 November 2009; Revised: 17 July 2010; Accepted: 8 August 2010; Published online: 15 November 2010 


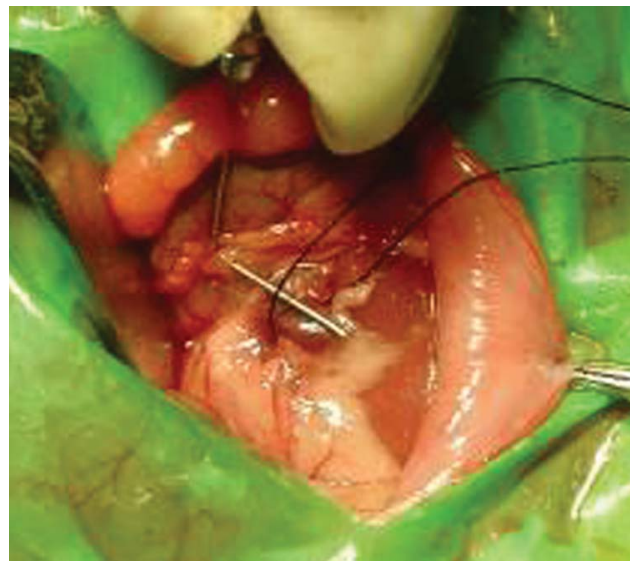

Figure 1 Renal vein was ligated with a needle and a 3-0 silk suture.

homogenates were transferred to $15-\mathrm{ml}$ screw-cap tubes and incubated at room temperature overnight. Then the tubes were centrifuged at $1800 \mathrm{~g}$ for $30 \mathrm{~min}$, the supernatant was aspirated and the pellet was dried to remove any traces of methanol. The water layer from the supernatant was extracted twice with $200 \mu$ l of diethyl ether. The extracted liquid was used for radioimmunoassay (Depp Biological Technology and Medical Products Co. Ltd, Tianjin, China).

Detection of apoptosis and determination of apoptotic index (AI) Apoptosis was detected by electron microscopy and TDT-mediated XdUTP nick and labelling (TUNEL) assay. Half of the testis was fixed in $3 \%$ glutaraldehyde for $2 \mathrm{~h}$ and fixed again with $1 \%$ buffered osmium tetroxide, dehydrated and embedded in EPon812. The tissue was located under light microscope. Ultrathin sections were cut and stained with uranyl acetate and lead citrate. Then the stained sections were observed and photographed under a Hitachi-600IV electron microscope (Shenzhen, China).

The TUNEL assay was performed to assess the level of apoptosis in every testis specimen. Sections were deparaffinized, rehydrated and incubated with proteinase $\mathrm{K}$ for $20 \mathrm{~min}$ at room temperature. Endogenous peroxidase was inactivated by immersing the sections in 3\% hydrogen peroxide. Fifty microlitres of the TUNEL assay solution (Roche Co. Ltd., Pleasanton, CA, USA) were added and the slides were incubated in a humidified chamber at $37^{\circ} \mathrm{C}$ in the transforming agent, peroxidase. The sections were incubated in $50 \mu \mathrm{l}$ of $3,3^{\prime}$-diaminobenzidine solution followed by counterstaining with haematoxylin.

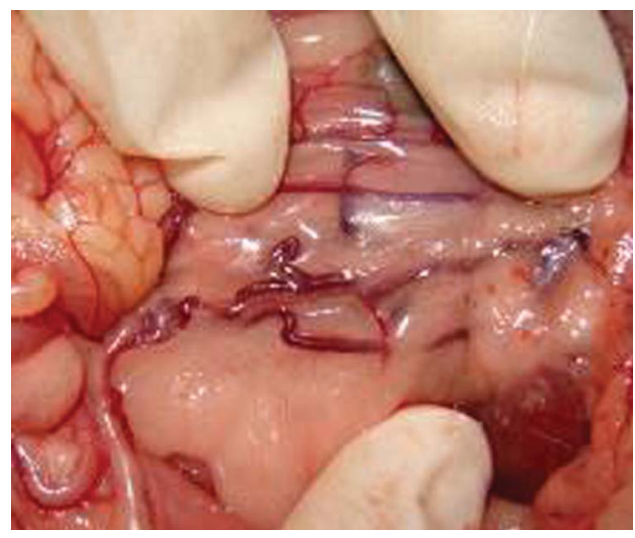

Figure 2 Experimental varicocele after 8 weeks.
The slides were dehydrated and cleaned. Each slide was examined under a microscope for any morphological changes characteristic of apoptosis in the germ cells and Leydig cells. The apoptotic nuclei were dark-yellow to yellowish, and the normal nuclei were blue. After acquisition of the images, AI was calculated using Image-Pro Plus4.5 illustration analysis software (Media Cybernetics, New York, USA). All the testes specimens were analysed for apoptosis and AI. The AI was calculated as the percent of positively stained germ cells or Leydig cells in five randomly selected fields at $\times 400$ magnification.

\section{Expression of StAR mRNA}

The StAR mRNA probe was from Rattus norvegicus steroidogenic acute regulatory protein (Star) mRNA (accession no.: NM_031555, $3402 \mathrm{bp}$; mRNA sequence of protein translation: 60-91) (Boster Biological Engineering Co. Ltd, Wuhan, China). The exact sequence of the StAR mRNA probe is provided as below:

1 ctctggaaga acaaatccet gggagcagca gcagcaactg cagcactacc acagaaagca 61 tgttactagc tacattcaag ctgtgtgctg ggagctccta cagacatatg cggaacatga 121 aaggactgag gcatcaagct gtgctagcca ttggccaaga gctgaaccgg agagccctag 181 gggaccccag tcctgggtgg atggtcagg tccggcgtcg gagctctcta cttggttctc 241 aactggaagc aacactctac agtgaccagg agctgtccta catccagcaa ggagaggaag 301 ctatgcaaaa ggccttggc atactaaca accaggaagg ctggaagaag gaaagccagc 361 aggagaatgg agatgaagtg ctaagtaagg tggtgccagg tgtgggcaag gtgttccgac 421 tggaggtgct gctagaccag cccatggaca gactctatga agaactggtg gaccgcatgg 481 aggccatggg agagtggaac ccaaatgtca aggaaatcaa ggtcctgaag aagattggaa 541 aagacacagt catcacccat gagctggctg cagcagcagc aggcaacctg gtggggcccc 601 gagacttcgt aagcgtacgc tgtaccaagc gtagaggttc cacctgtgtg ctggcaggca 661 tggccacaca ctttggggag atgectgagc aaagcggtgt catcagagct gaacacggtc 721 ccacctgcat ggtgcttcat ccactggctg gaagtccetc aaagaccaaa ctcacgtggc 781 tgctcagttat tgacctcaag gggtggctgc caaagaccat catcaaccaa gtcttatcac 841 aacccagat agagttcgcc agccacttgc gcaagcgctt ggagtccagc cctgcctctg 901 aggcccagtg ttaaggactg ccaccacat ctacctgcac gccattggaa gttctcacag 961 gaagtctgca agtctgttca ccttcagcca aggacaacga gaggggtagt agtcattaga 3361 gtcattggca gtctgattat aggtaaaaaa aaaaaaaaa aa

$5^{\prime}$-dig-cacacctggcaccaccttacttagcac- $3^{\prime} ; T_{\mathrm{m}}=62.7 ; 27 \mathrm{BASE}$

In situ hybridisation was carried out to detect the expression of StAR mRNA. Briefly, sections were deparaffinized and dehydrated, and all the endogenous enzyme activity in the cells was deactivated by $3 \% \mathrm{H}_{2} \mathrm{O}_{2}$ solution. Tissues were digested for $20 \mathrm{~min}$ with proteinase $\mathrm{K}$ to expose the mRNA fragments. Then the tissues were fixed in $1 \%$ paraformaldehyde. Hybridisation was carried out in the hybridisation medium in a moist chamber at $38{ }^{\circ} \mathrm{C}$ for $12 \mathrm{~h}$. The slides were washed and then incubated with digoxigenin-labelled StAR mRNA and streptavidin biotin chimera-alkali phosphatase at $37{ }^{\circ} \mathrm{C}$ for $40 \mathrm{~min}$. To visualize the hybridized probe, slides were incubated with bromo-chloro-indolyl phosphate/nitroblue tetrazolium. The slides were counterstained with fast red, dehydrated with ethanol and washed in dimethyl benzene. Image analysis was performed using Laserpix software.

\section{Statistical analysis}

All data were found to be normally distributed. Differences between groups are shown as the mean \pm standard deviation (s.d.) and analysed for statistical significance by analysis of variance using SPSS version 10.0 for Windows (SPSS, Chicago, IL, USA). $P<0.01$ was considered statistically significant.

\section{RESULTS}

Serum testosterone and intratesticular testosterone

Serum testosterone levels in the VC group decreased 4 and 8 weeks after the surgery but no significant differences were found when com- 
pared to the sham group $(P>0.05)$. Likewise, intratesticular testosterone levels in the VC group decreased 4 weeks after the surgery but were not significantly different from the sham group levels $(P>0.05)$. However, after 8 weeks, intratesticular testosterone levels in the VC group significantly decreased compared to the sham group $(P<0.01)$ (Table 1).

\section{Assessment of apoptosis in Leydig cells}

The normal appearance of Leydig cells under an electron microscope showed abundant mitochondria, smooth endoplasmic reticulum, lipid droplets, round or oval nuclei, evenly distributed peripheral chromatin and visible nucleoli. Leydig cell degeneration was marked by swollen mitochondria, expanded endoplasmic reticulum, increased number of apoptotic cells and contracted chromatin. AI values of Leydig cells in the experimental group after 4 weeks of the procedure were $18.73 \pm 12.80$ (left testis) and $16.96 \pm 13.97$ (right testis). The corresponding AI values in the control group were $9.23 \pm 8.26$ (left testis) and 8.91 \pm 5.96 (right testis). Eight weeks after the procedure, AI values in the experimental group were $28.35 \pm 22.82$ (left testis) and $17.66 \pm 13.80$ (right testis), and 9.24 \pm 7.04 (left testis) and 9.48 \pm 6.55 (right testis) in the control group. The mean AI values after 4 and 8 weeks in the experimental group were significantly higher than those in control group $(P<0.01)$.

\section{StAR mRNA expression in Leydig cells}

Four weeks after the procedure, StAR mRNA expression levels in Leydig cells of the left testis of rats in the VC group were significantly less than in the control group. However, after 8 weeks, the StAR mRNA levels were significantly reduced in the Leydig cells from both the right and the left testes of rats in the VC group compared with the control group (Table 2 and Figure 3).

\section{DISCUSSION}

VC is one of the leading causes of male infertility. It occurs in 15-20\% of the male population and causes infertility in $30-50 \%$ of married men. It is well known that VC leads to atrophy of testis, low sperm count and abnormal semen. ${ }^{15}$ Leydig cells produce testosterone in the testis. Several studies have focused on understanding how VC affects Leydig cell function. Although the scrotal septum exists within the scrotum, the bilateral pampiniform plexuses correlate with each other, and the pressure in dilative veins leads to contralateral spermatic vein. Additionally, Gat et al. ${ }^{16}$ found that VC is a bilateral disorder. However, it is difficult to explain the mechanism for alterations in the hormone level of the control testis in the experimental animals. Therefore, in this study we primarily focused on evaluating the serum and intratesticular testosterone levels, apoptosis and StAR mRNA expression.

A VC model was established by partial ligation of the left renal vein of the adolescent Sprague-Dawley rats. Only rats that showed a three-

Table 1 Concentrations of serum testosterone and intratesticular testosterone (ng ml$\left.{ }^{-1}\right)($ mean \pm s.d., $n=10)$.

\begin{tabular}{|c|c|c|c|c|c|}
\hline & \multicolumn{5}{|c|}{ Groups } \\
\hline & & \multicolumn{2}{|c|}{ Sham } & \multicolumn{2}{|c|}{ Varicocele } \\
\hline & & 4 weeks & 8 weeks & 4 weeks & 8 weeks \\
\hline $\begin{array}{l}\text { Serum } \\
\text { testosterone }\end{array}$ & & $1.30 \pm 0.35$ & $1.59 \pm 1.12$ & $1.01 \pm 0.38$ & $1.23 \pm 0.73$ \\
\hline $\begin{array}{l}\text { Intratesticular } \\
\text { testosterone }\end{array}$ & $\begin{array}{l}\text { left testis } \\
\text { right testis }\end{array}$ & $\begin{array}{l}28.67 \pm 3.57 \\
28.19 \pm 4.11\end{array}$ & $\begin{array}{l}29.41 \pm 2.35 \\
29.56 \pm 2.37\end{array}$ & $\begin{array}{l}26.85 \pm 3.42 \\
26.46 \pm 3.74\end{array}$ & $\begin{array}{l}24.84 \pm 4.56 * \\
25.04 \pm 3.90 *\end{array}$ \\
\hline
\end{tabular}

$* P<0.01$, compared with the corresponding sham group.
Table 2 Expression of StAR mRNA in Leydig cells (mean \pm s.d., $n=10$ ).

\begin{tabular}{lcclcc}
\hline & \multicolumn{2}{c}{ Sham } & & \multicolumn{2}{c}{ Varicocele } \\
\cline { 2 - 3 } \cline { 5 - 6 } \cline { 5 - 6 } & 4 weeks & 8 weeks & & 4 weeks & 8 weeks \\
\hline Left testis & $0.17 \pm 0.03$ & $0.21 \pm 0.03$ & & $0.16 \pm 0.02 *$ & $0.15 \pm 0.02 *$ \\
Right testis & $0.18 \pm 0.04$ & $0.21 \pm 0.05$ & & $0.17 \pm 0.03$ & $0.16 \pm 0.02 *$ \\
\hline
\end{tabular}

Abbreviation: StAR, steroidogenetic acute regulatory.

$* P<0.01$, compared with the sham group.

fold increase in the diameter of the spermatic veins post-operation were included in the experimental group. Ten rats per group were used for the study. None of the rats in the control group showed a similar dilatation of the left internal spermatic vein. The idea that the pathology of VC in humans is similar to that in rats provides a basis for the use of rat as model of $\mathrm{VC}$ and to understand the aetiology of $\mathrm{VC}$ in humans. Therefore, partial ligation of the left renal vein in adolescent rats to establish VC type is valuable. ${ }^{17}$

The European Association of Urology Guideline on Male Infertility states that serum testosterone levels decline in aged infertile men with VC. ${ }^{18}$ However, in our study, even 8 weeks after the procedure, serum testosterone levels were unchanged. Additionally, our data are not in agreement with previous study. ${ }^{19}$ We speculate that 8 weeks may not be long enough to observe such changes. Another possible explanation is that, since the adrenal gland can also secrete a certain amount of testosterone, it perhaps compensates for the loss due to VC. Therefore, the level of intratesticular testosterone declined earlier than the level of serum testosterone. Intratesticular testosterone concentration did not change after 4 weeks, but it declined significantly compared to the controls after 8 weeks. These data indicate that impairment of testis associated with $\mathrm{VC}$ is bilateral and gradual.

Because various pathological conditions are associated with VC, many researchers are studying the effects of $\mathrm{VC}$ on the levels of sex hormones in Leydig cells, which in turn may contribute to changes in pathological physiology. ${ }^{20}$ Because testosterone is produced in Leydig cells, it can be concluded that VC compromises the normal endocrine function of Leydig cells, thereby leading to suppression of secreted testosterone. Pituitary luteotropic hormone and follicle stimulating hormone levels were elevated via the feedback mechanism that regulates spermatogenesis by altering the stability of the endocrine environment. In humans, VC is known to result in increased serum testosterone levels, sperm count and sperm motility. ${ }^{11,21}$ Therefore, the impaired function of Leydig cells is reversible.

It has been shown that sufficient numbers of Leydig cells and every single cell that is capable of producing testosterone are needed to achieve normal testosterone levels. ${ }^{22}$ Interestingly, some apoptosis was also detected in the normal testis. It is believed that a certain degree of apoptosis could play a pivotal role in getting rid of injured, abnormal and decrepit cells, thereby maintaining stable quantity, quality and function of the Leydig cell population. On the contrary, excessive apoptosis could damage the body. Previously, it has been shown that ethane methanesulphonate or pituitary excision leads to apoptosis of Leydig cells and apparent decline in serum testosterone levels. ${ }^{23}$ Furthermore, excessive apoptosis of Leydig cells results in decreased testosterone levels and apoptosis of spermatogenic cells; however, exogenic testosterone supplementation was able to prevent apoptosis of spermatogenic cells. ${ }^{24}$ It has been shown that apoptosis of spermatogenic cells increased in rats with $\mathrm{VC}$, but the relationship between VC and apoptosis of Leydig cells is not yet known. In the present study, it appears that the level of apoptosis was higher in the left testis compared with that in the right. This suggests that the Leydig 


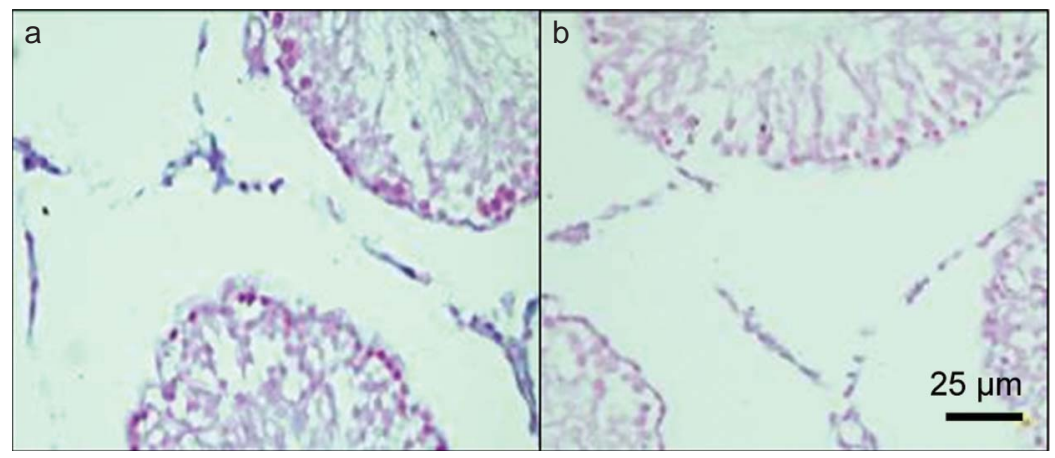

Figure 3 StAR mRNA expression is higher in the sham group (a) than in the experimental varicocele group (b) after 8 weeks of the procedure. StAR, steroidogenetic acute regulatory.

cell number decreases dramatically in the left side compared with that in the right side. However, it is difficult to explain the mechanism leading to suppression of testosterone levels in both the control testis and the experimental testis.

We studied Leydig cell apoptosis by TUNEL assay because DNA fragmentation is the end point of apoptosis. However, it may be worth analysing the expression of apoptosis-related genes including Fas and Bax. Apoptosis was obvious 4 weeks after the procedure, though serum testosterone levels were normal. It is possible that excessive apoptosis of Leydig cells occurs at early stages of testis impairment.

Besides the number of Leydig cells, the capacity of testosterone synthesis by a single cell is also an important factor that can affect serum and/or intratesticular testosterone levels. After synthesis of steroid hormone, the hydrophobic cholesterol is transferred to the internal membrane of mitochondria by StAR where the P450 scc enzyme is located, ${ }^{25,26}$ and transfer of cholesterol to the mitochondrial internal membrane is the rate-limiting step in steroid synthesis. Our results indicate that after 4 weeks, expression of StAR mRNA decreased in the left testis, and the right side was unaffected. However, after 8 weeks, the expression decreased bilaterally compared to that in the control group, which perhaps led to decreased testosterone synthesis. Though $\mathrm{P} 450 \mathrm{scc}$ is the rate-limiting step in steroid synthesis, Kallen et al. have shown that $\mathrm{P} 450$ scc is not regulated by the hormone in the early stage of synthesis. This indicates that StAR, and not P450scc, is the rate-limiting enzyme in steroid synthesis. ${ }^{27}$ Decreased StAR mRNA expression levels could interfere with testosterone synthesis, which could lead to suppression of the intratesticular testosterone levels. However, the precise mechanism by which StAR mRNA synthesis declines is unclear and warrants further investigation.

\section{CONCLUSION}

The decreased StAR mRNA levels induced by VC may result in reduced production of StAR protein, which may compromise transport of cholesterol, the substrate for androgen biosynthesis, into the mitochondria. This could result in poor testosterone production by the Leydig cells and eventually a decrease in testosterone levels. One of the obvious findings of the present study is that VC disrupts Leydig cell function by increasing apoptosis in the Leydig cells.

\section{AUTHOR CONTRIBUTIONS}

All authors contributed extensively to the work presented in this paper. Q. D. and D. Y. L. designed the study; J. J. L. and G. Y. performed experiments; D. Y. L. collected and analysed data and wrote the manuscript; Y. R. Y. and Q. D. gave technical support and conceptual advice. All authors discussed the results and implications and commented on the manuscript at all stages.

\section{COMPETING FINANCIAL INTERESTS}

The authors declare that they have no competing financial interests.

1 Velez de la Calle JF, Rachou E, le Martelot MT, Ducot B, Multigner L et al. Male infertility risk factors in a French military population. Hum Reprod 2001; 16: 481-6.

2 Naughton CK, Nangia AK, Agarwal A. Pathophysiology of varicoceles in male infertility. Hum Reprod Update 2001; 7: 473-81.

3 Uygur MC, Arik AI, Erol D, Ozer E, Ustün H. Quantitative evaluation of biopsy gun testis needle biopsy. Correlation between biopsy score of varicocele-bearing testis and sperm count. J Reprod Med 1999; 44: 445-9.

4 Mormandi E, Levalle O, Ballerini MG, Hermes R, Calandra RS et al. Serum levels of dimeric and monomeric inhibins and the degree of seminal alteration in infertile men with varicocele. Andrologia 2003; 35: 106-11.

5 Turner TT. The study of varicocele through the use of animal models. Hum Reprod Update 2001; 7: 78-84.

6 Redmon JB, Carey P, Pryor JL. Varicocele-the most common cause of male factor infertility? Hum Reprod Update 2002; 8: 53-8.

7 Mostafa T, Anis TH, El-Nashar A, Imam H, Othman IA. Varicocelectomy reduces reactive oxygen species levels and increases antioxidant activity of seminal plasma from infertile men with varicocele. Int J Androl 2001; 24: 261-5.

8 Santoro G, Romeo C, Impellizzeri P, Ientile R, Cutroneo G et al. Nitric oxide synthase patterns in normal and varicocele testis in adolescents. BJU Int 2001; 88: 967-73.

9 Mehraban D, Ansari M, Keyhan H, Sedighi Gilani M, Naderi G et al. Comparison of nitric oxide concentration in seminal fluid between infertile patients with and without varicocele and normal fertile men. Urol J 2005; 2: 106-10.

10 Castro-Magana M, Angulo M, Canas A, Uy J. Leydig cell function in adolescent boys with varicoceles. Arch Androl 1990; 24: 73-9.

11 Cayan S, Kadioglu A, Orhan I, Kandirali E, Tefekli A et al. The effect of microsurgical varicocelectomy on serum follicle stimulating hormone, testosterone and free testosterone levels in infertile men with varicocele. BJU Int 1999; 84: 1046-9.

12 Ghosh PK, York JP. Changes in testicular testosterone and acid and alkaline phosphatase activity in testis and accessory sex organs after induction of varicocele in Noble rats. J Surg Res 1994; 56: 271-6.

13 Zheng YQ, Zhang XB, Zhou JQ, Cheng F, Rao T et al. The effects of artery-ligating and artery-preserving varicocelectomy on the ipsilateral testes in rats. Med Sci Monit 2008; 14: BR122-126.

14 National Research Council. Guide for the Care and Use of Laboratory Animals. Washington, DC: National Academy Press; 1996. p119.

15 Hadziselimovic F, Herzog B, Liebundgut B, Jenny P, Buser M. Testicular and vascular changes in children and adults with varicocele. J Urol 1989; 142(2 Pt 2): 583-5; discussion 603-5.

16 Gat Y, Bachar GN, Zukerman Z, Gornish M. Varicocele: a bilateral disease. Fertil Steril 2004; 81: 424-9.

17 Turner TT, Howards SS. The venous anatomy of experimental left varicocele: comparison with naturally occurring left varicocele in the human. Feril Steril 1994; 62: 869-75.

18 Dohle GR, Colpi GM, Hargreave TB, Papp GK, Jungwirth A et al. EAU guidelines on male infertility. Eur Urol 2005; 48: 703-11.

19 Younes AK. Low plasma testosterone in varicocele patients with impotence and male infertility. Arch Androl 2000; 45: 187-95. 
20 Su LM, Goldstein M, Schlegel PN. The effect of varicocelectomy on serum testosterone levels in infertile men with varicoceles. J Urol 1995; 154: 1752-5.

21 Gat Y, Gornish M, Belenky A, Bachar GN. Elevation of serum testosterone and free testosterone after embolization of the internal spermatic vein for the treatment of varicocele in infertile men. Hum Reprod 2004; 19: 2303-6.

22 Boujrad N, Guillaumin JM, Bardos P, Hochereau de Reviers MT, Drosdowsky MA et al. Germ cell-Sertoli cell interactions and production of testosterone by purified Leydig cells from mature rat. J Steroid Biochem Mol Biol 1992; 41 677-81.

23 Tapanainen JS, Tilly JL, Vihko KK, Hsueh AJ. Hormonal control of apoptotic cell death in the testis: gonadotropins and androgens as testicular cell survival factors. Mol Endocrinol 1993; 7: 643-50.
24 Henriksén K, Hakovirta H, Parvinen M. Testosterone inhibits and induces apoptosis in rat seminiferous tubules in a stage-specific manner: in situ quantification in squash preparations after administration of ethane dimethane sulfonate. Endocrinology 1995; 136: 3285-91.

25 Hales DB, Allen JA, Shankara T, Janus P, Buck S et al. Mitochondrial function in Leydig cell steroidogenesis. Ann NY Acad Sci 2005; 1061: 120-34.

26 Pollack SE, Furth EE, Kallen CB, Arakane F, Kiriakidou M et al. Localization of the steroidogenic acute regulatory protein in human tissues. J Clin Endocrinol Metab 1997; 82: 4243-51.

27 Kallen CB, Arakane F, Christenson LK, Watari H, Devoto L et al. Unveiling the mechanism of action and regulation of the steroidogenic acute regulatory protein. Mol Cell Endocrinol 1998; 145: 39-45. 